\title{
The Processes of Location Study for Developing Economic Zones under Public Private Partnership Model: Country Study on Bangladesh
}

\author{
Md. Mahmudul Alam* \\ $\mathrm{PhD}$ Student \\ Institute for Environment and Development (LESTARI) \\ Universiti Kebangsaan Malaysia \\ 43600 UKM Bangi, Selangor Darul Ehsan \\ Malaysia \\ Contact No. +60162799091 \\ Email: rony000@gmail.com \\ Md. Abu Rashed \\ Sr. Consultant, Project Development \\ Infrastructure Investment Facilitation Center (IIFC) \\ An enterprise of Economic Relations Division (ERD) \\ Ministry of Finance, Government of Bangladesh \\ Dhaka, Bangladesh \\ Contact No. +8801819830140 \\ E-mail: arashed@infra-bd.com
}

*Corresponding Author

\section{Citation References:}

Alam, M.M., and Rashed, M.A. 2011. The Processes of Location Study for Developing Economic Zones under Public Private Partnership Model: Country Study on Bangladesh, Journal of Economics and Business Research, Vol. 17(2), pp. 51-63. Available at < http://www.uav.ro/files/jebr/JEBR_No_2_2011.pdf>

This is a pre-publication copy.

The published article is copyrighted by the publisher of the journal. 


\title{
The Processes of Location Study for Developing Economic Zones under Public Private Partnership Model: Country Study on Bangladesh
}

\author{
Md. Mahmudul Alam*, Md. Abu Rashed ${ }^{\dagger}$
}

\begin{abstract}
In spite of the complexity in defining the boundary, the concept of Economic Zones (EZ) has been evolved as a way forward for the government of the developing countries for enhancing the national trade. Similarly the recent phenomenon of widespread Public Private Partnership (PPP) practices especially in infrastructure sector is also providing a window to develop many of such economic zones through PPP model as EZ typically is capital intensive. Bangladesh has discrete success both under PPP and EZ regime. However, developing EZ under PPP model has few commercial complexities as both the public and private sector need to bear some roles and obligations one of which is selection of appropriate location for EZ development. The location study for PPP EZ development therefore receives paramount attention both from developer and lenders perspective. Such location study generally is not typical project site study by nature, rather it is more economic concentrated. This paper will try to identify the factors that are essential to consider for conducting these location studies based on the examples of Bangladesh. The paper will also identify the appropriate methods and approaches required for successful EZ development through PPP.
\end{abstract}

Key Word: Economic Zone, Location Study, Public Private Partnership, Infrastructure, Bangladesh

\section{Introduction}

A nation's export competitiveness can be achieved through its trade (Nihon, 2005), development of infrastructure, and opportunities of special economic privileges- lower taxes and rebate to a liberalized economy. As country-wide development of infrastructure is expensive and implementation of structural reforms requires time due to various socioeconomic and political realities, Export Processing Zones (EPZs) are considered a strategic tool for promotion of exports (Mondal, 2001). In order to promote export competitiveness, economic zones have emerged as a trade policy with special emphasis on outward orientation. At the same time, economic zone also boost up inward industrial growth. Areas with special economic privilege i.e. lower taxes and rebates have been common since $16^{\text {th }}$ century but it did not impact the world trade. After 1960, impact of these specific areas became prominent in the world trade and gained special terminology as Economic Zones or EZ (Guangwen, 2003). Now Economic zones are considered as a powerful tool for integration with world economy.

\footnotetext{
Md. Mahmudul Alam, Institute for Environment and Development (LESTARI), Universiti Kebangsaan Malaysia, 43600 UKM Bangi, Selangor Darul Ehsan, Malaysia, E-mail: rony000@gmail.com; Tel: +60162799091.

${ }^{\dagger}$ Md. Abu Rashed, Sr. Consultant, Project Development, Infrastructure Investment Facilitation Center (IIFC), An enterprise of Economic Relations Division (ERD), Ministry of Finance, Government of Bangladesh, E-mail: arashed@infra-bd.com, Contact No. +8801819830140.

* The views expressed in the research paper are authors' own and do not reflect those of the organizations in which they work.
} 
Policymakers must be aware of the fact while economic zones bring about economic growth; they are not limited within themselves. Economic zones generate investment, employment, exports, and help to gain cost reductions from scale economies. The real value of economic zones depends on their ability to stimulate widespread growth through linkages with the domestic economy and to catalyze nationwide reforms by offering an opportunity for pilots.

Comparing benefits to countries with export zones to those without, there are about 102 countries with export zones and 126 countries which do not have them, they can be compared on economic parameters like export growth rate, market share etc. Countries with zones, gained market share to $75 \%$ while those without zones fell to $25 \%$ (Bolin, 2007) indicates that countries are adopting economic zones as a competitive strategy for growth, development and to achieve trade competitiveness globally.

Taking the case of Bangladesh, the Export Processing Zones (EPZs) have been relatively successful in addressing some of the key competitiveness issues facing foreign and domestic producers operating in Bangladesh. EPZs provide serviced land, reliable infrastructure, adequate logistics, and an authority which attends to the needs of the zone's tenants. However, the current EPZ model has its limits in terms of cumulative impact on growth prospects since the few EPZs in operation provide little in the way of linkages with, and spillovers to, the economy as a whole and they have been built, owned and operated exclusively by the public sector with increasingly limited resources. The Public sector entity like BEPZA exclusively develops and operates such export oriented zones except that of KEPZ. But essentially EPZ's are completely export oriented with almost no consideration about the domestic market. This is where the Economic Zone (EZ) plays one of the most vital roles. An economic zone allows the tenants to go for both export and meet domestic demand.

Drawing from numerous examples of successful Economic Zones (EZs) around the world as well as Bangladesh's own experience with the existing EPZ, the Government of Bangladesh (GoB) is acutely aware of the potential direct and indirect impacts that could be realized by scaling up to a more modern, generalized regime for EZs as a tool for sustainable and globally competitive economic development. The GoB, in order to realize the EZ potential, has launched an effort to develop a new EZ policy regime for Bangladesh based on good economic and social practices in their operation and commercial principals in their development and management. This research will identify the way of location study for identifying and developing new economic zones in the country with concentrating on a special type of ownership criteria, Public Private Partnership.

\section{PPP Model for Developing EZs in Bangladesh}

"PPP" means Public-Private-Partnership in which Government engages the private sector through a strong contractual framework, to carry out investment and/or management of certain infrastructure services. In this type, Economic Zones Developed through PPP, a Government agency plans, carries out feasibility study, acquires land, obtains consents \& approvals, and transfers the further development and management of the zone to a private individual, group, company or group, whether local or foreign or Non-resident Bangladeshis through (a) a transparent PPP tendering process for a Zone Developer like development of the first ever High-Tech Park in Bangladesh being executed by Bangladesh Computer Council under Ministry of Science, Information and 
Communication Technology, (b) a Recognized Industry Association like EZ for BGMEA or EZ for BAPI through a negotiated process. The extent of participation of GoB in this new EZ policy regime will be from the front-end activities up to the award to the Zone Developer or Recognized Industry Association. Any aspect of economic zone infrastructure or services will be eligible for PPP.

The Private Sector Development Support Project (PSDSP) is a multi donor project has supported the creation of a newly launched technical assistance fund called the Bangladesh Investment Climate Fund (BICF) as a separate entity, managed by IFC. As one of its central activities, BICF has embarked on a program of support to the GoB to develop and implement a new EZ regime with an emphasis on a greater role for the private sector in zone development, service delivery and operation. In parallel the BICF will be supporting the development of prototype PPP models for both overall zone development and operation and provision of specific services in order to assist in developing the specific PPP arrangements for the investment sub-projects to be funded by the PSDSP.

The Government of Bangladesh has already identified few locations to develop economic zones through PPP. BCC under MOSICT is in the process of developing a high-tech park (EZ) and has already acquired 232 acres of land at Kaliakor in Gazipur district. The Comilla EPZ is located in the Comilla old airport area, 167 kilometers from Chittagong port and 97 kilometers from Dhaka. The area of the existing Comilla EPZ is 258 acres and another 478 acres has been proposed for the extension through PPP being implemented by BEPZA. Project sites for the RMG and the API Industrial Park have been selected at Bausia in Gazaria thana of Munshigong district in consultation with Bangladesh Garment Manufactures and Exports Association (BGMEA) and Bangladesh Association of Pharmaceutical Industries (BAPI), the trade associations which represent the prime tenants for these two proposed EZs. These two proposed economic zones will be implemented by BSCIC. The industrial park for BAPI has already been approved by ECNEC and an amount of fund has been allocated for developing the site.

This PPP-Based Development Track is of essential importance to the development of economic zones in Bangladesh. The focus of the new zones strategy should be to develop new and larger zones in locations chosen based on demand and feasibility assessments, under a liberalized framework where different types of industrial activities can coexist under established land use criteria, and with a higher level of infrastructure and value added services developed by the private sector and offered to tenants on commercial principles. The "hybrid" nature of this Track speaks of the co-existence of industrial activity geared towards the domestic market as well as a free zone area within the same property. By removing export barriers and allowing unhindered sales to the domestic market on a duty-paid basis, there will be greater integration of economic zones with the broader economy. The Government's main role would be to regulate economic zone activities, promote the zone regime, and aggressively identify, assemble, and make available land suitable for industrial development through PPPs.

\section{Factors of Location Study for EZs}

Government of Bangladesh in its initiative to develop an economic zone regime in the country as realized through its adaptation of EZ policy and the subsequent EZ ordinance provides emphasize on the importance of selecting suitable location for developing potential economic zones in the country. EZ as specialized locations has been found to be efficient in business process especially that dealing with large volume of business 
transactions and facilities through advanced infrastructure and other facilities to enhance trade competitiveness within and outside of the country. Earlier industrial concepts largely considered the broader guidelines and framework analysis that happened in different parts of India while establishing industrial parks especially with IT industries that does not require much concentration on site specific analysis. Here the location and spatial diversification were simply determined by an adjustment between location and weight distance characteristics of inputs and outputs (Weber, 1929). But recently it has been observed as numbers of exclusive experiences have been evidenced that selecting appropriate location is most critical for success of any particular zone.

As mentioned, global experiences realized through number of developers competing for an economic zone in PPP highlighted location decisions of firms an important strategic decision depending on several factors. Various recent empirical research and literature suggests that location can be a contributing factor to the competitiveness of a firm (Karakaya \& Canel, 1998). Empirical studies suggest that EZ's located in developed areas have higher chances of pursuing agglomeration and more successful compared to those which are located in semi or undeveloped areas (IDFC, 2001). These results out the importance of agglomeration and linkage effect as well as overall market analysis of the economic zones more critical to utilize if EZ's are established in comparatively lower level adjustment in terms of location criterions.

Empirical studies on the location of a firm have brought out list of factors which can be summarized and inferred upon. Schemenner (1979, 1982), Galbraith (1985, 1990), and Galbraith and Galbraith (1988) encompasses availability and proximity to other industries and supplier/resources in the region which leads to forming of business transaction as decider of location of a firm.

Fulton (1971), Schemenner (1979), Blair and Premus (1987), Schemenner et al. (1987), Galbraith and De Noble (1988), Hekman (1992), De Noble and Galbraith (1992), Stonebraker and Leong (1994) focused on area's business climate, attitude of local and state government, state and local government incentives, transportation costs and facilities, proximity to highways, availability of utilities and services, tax structure and rates, local and physical infrastructure, availability of infrastructure etc.

Fulton (1971), Schemenner (1979, 1982), Hack (1984), Galbraith (1985, 1990), Schemenner et al. (1987), Blair and Premus (1987), Galbraith and De Noble (1988), Karakaya and Stahl (1989), Hekman (1992), De Noble and Galbraith (1992), Stonebraker and Leong (1994) emphasized on labor productivity and attitude toward productivity, cost of labor, availability of labor, availability of skilled labor, availability of unskilled labor, availability and transfer of qualified technical and managerial personnel, land availability for building and expansion, cost of land, cost of construction, financing opportunities, banking services, and access to raw materials, that means availability and quality of men, machine, money, material including land- which are traditionally considered as the factors of production in economic literature.

From the findings and suggestions of various literatures, proximity to supplier/resources, availability of infrastructure, tax-concession, govt. and institutional support and quality and availability of men, machine, money, and material are the important factors affecting the location of a firm. It is important to understand that the number of EZs that will be developed in the country strictly depends on the availability of land and its potentiality for 
establishing an economic zone. So, more the number of potential locations mean more the possibility for having such zones in the country.

\section{The Way of Conducting Location Study for EZs}

In general the overall methodology for selecting a site and conducting location study on it can be divided largely by the following activities.

\section{Step-1: Identification of Broader Area (Upazilas) for Site Selection}

The upazilas should be selected based on the overall infrastructure facility, connectivity, level of service availability including the utility services, and industrial activity. However, availability of the raw materials and labor force also acts as critical factor for selecting specific upazila. More specifically, an appropriate location should be in those areas where the road and/or river communication network, electricity, gas/fuel supply for wholesale, industrial and domestic use, regional connectivity, proximity to a township or a commercial hub, city or metropolitan, existing industrial activity in the vicinity etc are available. However, other specific issues need to be considered, such as, access to markets, type of currently available industry, number of available industrial area, mineral resources availability, unemployment rate, total land area, total road area as \% of total land area, Pakka road area, road and rail connectivity, distance from Zila headquarter, number of available ports- land port, river port, air port etc.

\section{Step-2: Primary Selection of Sites for Location Study}

Based on the minimum required land area (in Bangladesh it is 25 acres), some sites have to be identified from the selected upazilas. However, in Bangladesh, the site would not be within 20 kilometer radius of Dhaka and Chittagong cities, within $10 \mathrm{~km}$ radius of divisional headquarters, and $7 \mathrm{~km}$ of district headquarters. ${ }^{*}$ This is expected to be an exhaustive list and will not include detailed analysis for site selection. More sites should be planned to be included in this list to conduct the detailed location studies. However, a screening mechanism can be applied to shorten the list based on the site specific location criteria as mentioned in the next section, if the list is found to have vast number of potential sites based on the primary selection.

The list needs be prepared based on the site visit within the upazila. However, interviews and visit to the local land authority will be helpful to identify the primary sites. The specific activities may include but not limited to the following:

- Visit LGED for overall and detailed upazila Map

- Visit local land authority for the same

- Interview the officials of local land authority

- Interview other relevant officials like T.N.O, commissioner (Ac Land), chairman, and local people

- Identify the areas for site selection within the upazila (an exhaustive and detailed list)

- Visit the area and primary selection of sites for location study

For successful analysis and for proper information, the approval process and cooperation should be ensured and streamlined especially for the local authorities like T.N.O, commissioner (Ac Land), chairman, etc.

\footnotetext{
‡ Draft copy of "Bangladesh Economic Zones Policy 2008".
} 


\section{Step-3: Conducting Location Studies on Selected Sites}

A similar approach as explained above has to be adopted for carrying out the location study of selected sites. The area of the land needs to measure and also to understand the nature and type of the land along with the adjacent area. The specific site related study may include to the following:

Study of site location: The identified site should be studied with respect to:

- Physical features

- Land Valuation

- Location with respect to other magnets like major shopping zones, commercial zones, prime residential areas etc.

- Accessibility and connectivity linkages.

- Land utilization and economic activities in the neighborhood.

Location Analysis of the Site: This site specific location analysis must include the following:

- Position and Land Mark of the Proposed Site

- Salient Features of the proposed site:

- Approach road connecting the major distributor highway

- Tentative length and width of the Approach road

- The main rail line

- Any feeder road along with the measurement

- Any settlements in the land and relevant description

- Availability of river communication network

- Regional connectivity, proximity to a township or a commercial hub

- Other Observations:

- Whether any irregular undulation in the site

- Whether any of landfill is required and if an, the approximate amount for land filling

- Study on Adjacent area

- Whether there is any resettlement issue exist

- Overall other observation and suggestions

\section{Step-4: Conducting Basic Market study as a part of location study}

The purposes of the basic market study are to review the commercial issue- a review of commercial trends to assess the potential of the proposed site, and investors' issueassessment of demand and analysis of the industry and relevant market. The demand assessment study would be critical in terms of feasibility of a site. Under a location study, some basic demand assessment can be carried out through assess attractiveness of proposed site to potential investors, analyze the expected return for potential units in the EZ, site-specific industry analysis for each identified industry segment, and basic industry analysis.

Under the basic industry and market analysis, the information on the following issues to be collected to understand the nature of the market and industry adjacent to the specific selected site:

- Type and nature of Industrial area adjacent to the site 
- Size of the individual and overall industries

- Scope for new types of industries

- Types of raw materials and inputs available in the location

- Type of import and export in the vicinity

- Land purchase and development Cost

- Demographic features of the locality

- Basic economic activities and living standard of the area

- Level of Employment, availability, nature-skilled/unskilled, and cost of Labor

- Nature of infrastructure facilities to nearby market and industrial hub

- Any special feature if any related to the site referring to the market and industry like existence of government facility or decisions or any planned industrial activity etc.

- Availability of utility and other services etc

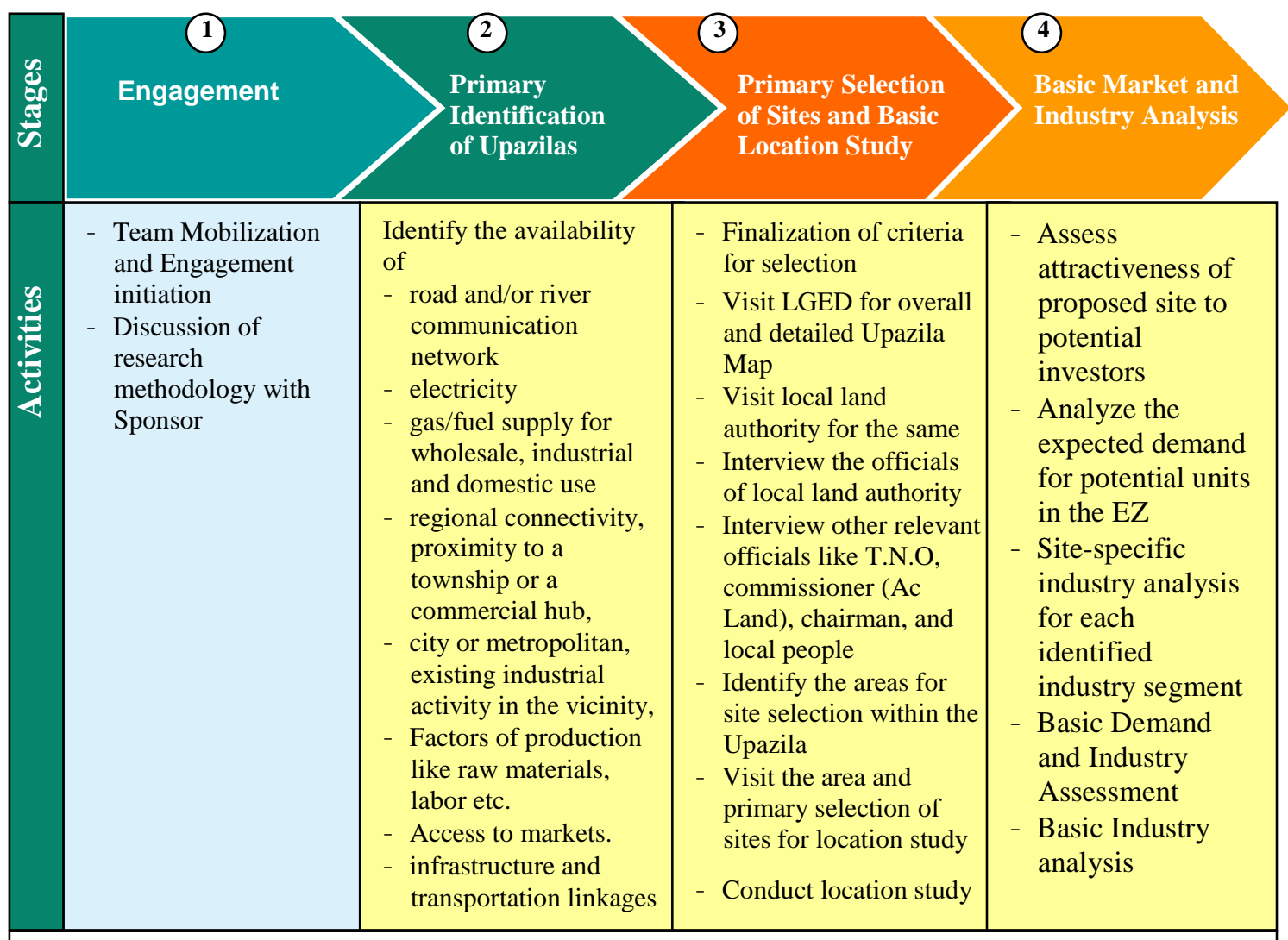

Figure 1: Overall Approach and methodology of Conducting Location Study for EZs

\section{Conclusion}

Bangladesh has good experiences about EPZ but currently there is no economic zone in the country. Few economic zones are under process and very few location studies are going on in major districts of Dhaka, Chittagong, and Sylhet Divisions. To reduce the regional disparity, Zila wise study of potential locations for EZs is essential. Moreover, to protect the urbanization and income inequality, upazila level location study for EZs is very important. Initial screening for EZs in Bangladesh through location study will be helpful to prepare a long list of potential sites so that a long term plan with feasible types of developing modality for EZs will be easy to prepare by the policy makers. 
After finalizing the sites, selecting through location study, it should be categorized separately based on size of the area, type and nature of land, offside infrastructure facilities, availability of inputs, labor and its nature, local market structure/ specific economic condition, and types of possible industry to setup in the area. The separate list and separate valuation is required, because the potential weight of these factors differs to the ownership model of EZs. If the EZ is developed by PPP model any of these hinders can be solved easily, which may not possible through only public or only privet sector. So, only preparing a common list through indexing or ranking of sites is not suitable at all. However, categorization of sites - most potential sites, moderately potential sites, and less potential sites- can be considered as a valuable source for the government, private sector or the donor community who are actively pursuing to establish the economic zones regime in the country.

In Bangladesh, the PPP model acts as a significant catalyst for establishing successful Economic Zones where adjacent developing utility services, especially power and gas supplies, access to infrastructure and transportation linkages are not suitable for private sector. Typically for infrastructure development, like economic zones might require government involvement not only in the form of subsidy or other assistance but also for regulatory issue. In economic zones development, through the PPP model, some significant infrastructure development like land filling etc. including offside infrastructure facilities can be developed resulting more viability for establishing EZ regime in the country.

\section{References}

Blair, J. P., and Premus, R. (1987). "Major factors in industrial location: a review," Economic Development Quarterly, 1(1), 72-85.

Bolin, R. (2007). "Why Export Processing Zones are Necessary". Retrieved November 25, 2007, from World Economic Processing Zones Association Web site: http://www.wepza.org

De Noble, A.F., and Galbraith, C.S. (1992). "Competitive strategy and high technology regional/site location decisions: a cross country study of Mexican and US electronic component firms," The Journal of High Technology Management Research, 3 (1), 19-37.

Fulton, M. (1971). "New factors in plant location," Harvard Business Review, 49, 166168.

Galbraith, C. and De Noble, A. F. (1988). "Location decisions by high technology firms: a comparison of firm size, industry type and institutional form," Entrepreneurship Theory and Practice, 13, 31-48.

Galbraith, C.S. (1985). "High technology location and development: the case of Orange County," California Management Review, 28, 98-109.

Galbraith, C.S. (1990). "Transferring core manufacturing technologies in high technology firms," California Management Review, 32, 56-70.

Guangwen, M. (2001). "The theory and practice of free economic zones: A case study of Tianjin," People republic of China. Germany: University of Heidelberg.

Hack, G. D. (1984). "The plant location decision making process." Industrial Development, 153, 31-33.

Hekman, J. S. (1992). "What are businesses looking for?" Federal Reserve Bank of Atlanta Economic Review, 67, 6-19.

Infrastructure development finance company (IDFC 2001), report on SEZ. 
Karakaya, F., and Stahl, M. J. (1989). "Barriers to entry and market entry decisions in consumer and industrial markets," Journal of Marketing, 53, 80-91.

Karakaya, F. and Canel, C. (1998). "Underlying dimensions of business location decisions," Industrial management \& data systems. 98/7, 321-329.

Mondal, A.H. (2001). "Role of the Export Processing Zones in the Industrialization Process of Bangladesh: Lessons for the Future," in Rahman, R. I. (ed.), Performance of the Bangladesh Economy: Selected Issues, Bangladesh Institute of Development Studies, Dhaka, pp 93-122.

Nihon, K. L., Whitwell, J., and Yao, S. (2005). "A growth model for china's special economic zone," Pacific Economic Review, 10(4), 439-449.

Schemenner, R. W. (1979). "Look beyond the obvious in plant location," Harvard Business Review, 57, 126-132.

Schemenner, R. W. (1982). "Making Business Location Decisions," Englewood Cliffs. NJ: Prentice-Hall.

Schemenner, R. W., Huber, J., and Cook, R. (1987). "Geographic differences and the location of new manufacturing facilities," Journal of Urban Economics, 21, 83104.

Stonebraker, P. W. and Leong, G. K. (1994). "Operations Strategy: Focusing Competitive Excellence," Prentice Hall.

Weber, A. (1929). "The theory of location of an industry," Chicago: The University of Chicago press. 